\title{
A hybrid approach for selecting material handling equipment in a warehouse
}

\author{
Thomy Eko Saputro ${ }^{\mathrm{a} *}$ and Babak Daneshvar Rouyendegh (Babek Erdebilli) ${ }^{\mathrm{b}}$ \\ ${ }^{a}$ University of Muhammadiyah Malang, Jl. Raya Tlogomas 246, Malang 65144, Indonesia; ${ }^{b}$ ATILIM University, Klzılcaşar \\ Mahallesi-İncek, Ankara 06836, Turkey
}

(Received 7 September 2014; final version received 15 April 2015)

\begin{abstract}
Warehouse operations are closely related to material handling activities. Loading, unloading, transporting and picking material constitute a huge part of the activities. In order to handle material properly as well as to contribute value to the material, the operator and the environment, utilizing Material Handling Equipment (MHE) is required. The selection of proper MHEs requires great focus since its consideration is linked to mutli-criteria and multi-objective decision making problems. Here, a hybrid method is proposed to address the MHE selection problem. An approach that integrates the entropy based hierarchical fuzzy Technique for Order Preference by Similarity to an Ideal Solution (TOPSIS) and Multi-Objective Mixed Integer Linear Programming (MOMILP) is used for seeking the best alternative. The evaluation of alternatives is performed based on both subjective and objective criteria. Subjective weights are derived from a fuzzy Analytic Hierarchy Process (AHP). To deal with objective criteria, the entropy method is adopted to determine the weights, and the integrated weights are also calculated. The alternatives are rated by using fuzzy TOPSIS. For final execution of the selection, an MOMILP model is developed incorporating two goals, namely to minimize the disadvantage of material handling operation and to minimize the total cost of material handling. The AUGMented E-CONtraint method (AUGMECON) is used to solve the model. A case study is given to illustrate the method. The results show the effectiveness of the hybrid method in complex decision making.
\end{abstract}

Keywords: MHE selection; warehouse operations; MCDM; fuzzy logic; MOMILP

JEL Classification: C02; C61; D81; C44

\section{Introduction}

Material handling can be defined as activities concerning the movement, storage, control and protection of the whole flow of materials within and/or across sites such as to/from the manufacturing plant, warehouse, and supply chain in order to handle material properly. In general practice, material handling tends to incur costs as a result of consuming resources in terms of labour, capital, facilities and equipment rather than saving. Therefore, material handling should be worth the cost or expense incurred through giving added value to the material itself and resulting in long-term advantage to the whole process. Moreover, in an industrial manufacturing company, material handling may account for $25 \%$ of all employees, $55 \%$ of all company space, $87 \%$ of production time, and 15 up to $75 \%$ of the total cost of product (Tompkins, White, Bozer, \& Tanchoco, 2003).

Operations frequently occurring in a warehouse relate to material handling linked to storage and movement of product. To complete the essential functions of a warehouse properly, the appropriate procedure for material handling should be well determined, whether it is performed by a fully automated system, a semi-automated system or manually. For a warehouse that applies a semi-automated system for handling material, a handling device or equipment such as an industrial truck operated by a human agent is needed. The use of appropriate material handling equipment makes a

\footnotetext{
*Corresponding author. Email: thoms.engineering@gmail.com; Tel.: + 628-213-975-2313
}

major contribution to the success of warehouse operations, such as achieving efficiency of space or layout and reducing the cost of material handling. Even though utilizing a manual material handling system is always much less expensive than using automated machines or equipment, using manual equipment for heavy tasks is unsafe for workers or operators because of the risk of causing injury in the operation. In addition, in today's industrial revolution, the issue on occupational health and safety is of real concern. In some countries, manual material handling is performed under the authority of either government or private regulators. In such an environment, dependency on manual material handling systems is not an option, and selecting the appropriate material handling equipment is of the highest importance. The complexity causing the challenge to the material handling selection process is generally triggered by physical facility constraints, material characteristics, multiple criteria (Matson, Mellichamp, \& Swaminatham, 1992), uncertainty in the operation and the diversity of material handling equipment (Karande \& Chakraborty, 2013).

This study aims to determine the appropriate material handling equipment to be operated in a warehouse using the proposed approach. We present a multi-criteria and multiobjective Material Handling Equipment (MHE) selection problem in order to examine and solve the problem from all perspectives. Hence, a hybrid method is chosen to incorporate the complex selection process so that enhanced decision making leading to a sophisticated solution can be realized. Our hybrid approach involves two different methods, one being Multi-Criteria Decision Making (MCDM) based and the other being optimization based, 
namely an approach that integrates an entropy based hierarchical fuzzy Technique for Order Preference by Similarity to an Ideal Solution (TOPSIS) and MultiObjective Mixed Integer Linear Programming (MOMILP). At first, the fuzzy approach is applied to both the Analytic Hierarchy Process (AHP) and TOPSIS in order to incorporate uncertain Decision Makers' (DMs') opinions. In addition, it is applied because the evaluation parameters of MHE cannot be precisely measured or predicted. Providing exact numerical values for criteria and evaluating inexact feelings and perceptions given uncertain information and vague human feelings is obviously difficult (Kutlu \& Ekmekçioğlu, 2012). Hence, fuzzy set theory is utilized so that classical AHP and TOPSIS are applicable for vague human thoughts. AHP is adopted to determine subjective weight in order to provide more measurable criterion weights according to human judgment given a lack of information. Moreover, we interpret the in-depth evaluation of the MHE selection problem through a multi-level structure so that the extension of criteria weight determination can be more selective, and AHP is effective for representing this case whereas the entropy method is applied for determining objective weight because of its ability to reflect the essence of the information and to measure the usefulness of provided data as well as to grasp the actual conditions of evaluation criteria (Guo \& Zhao, 2014; Zou, Yun, \& Sun, 2006). TOPSIS is adopted to evaluate the alternatives because it brings some advantages: the TOPSIS procedure matches the human decision selection process; the algorithm is easy to calculate and implement; the best and worst solutions are considered simultaneously through a scalar value (Hwang \& Yoon, 1981); and the performance measures of alternatives under certain criteria can be visualized on a polyhedron (Shih, Shyur, \& Lee, 2007). With a view to comprehensive decision making, the selection process is conducted by considering holistic parameters. To achieve the objectives, the MHE selection problem is constructed as an MOMILP problem.

\section{MHE selection: the criteria literature}

The evaluation criteria for MHE selection can vary depending on particular factors such as operation types, equipment category, etc. In the following paragraphs, the consideration of MHE selection is explained with reference to studies in the literature.

In cellular manufacturing systems, material handling equipment has been selected by evaluation according to three major categories, i.e. cost, benefit and compatibility (Braglia, Gabbrielli, \& Miconi, 2001). MHE selection deals with multiple alternatives and multiple cells. The evaluation criteria involving the three major categories can be structured in detail as shown in Table 1.

Momani and Ahmed (2011) defined criteria and subcriteria for MHE evaluation by adopting and modifying MHE evaluation criteria from different past studies conducted by Kulak (2005) and Chakraborty and Banik (2006). The criteria were developed to incorporate MHE for carrying material from the packaging department to the main storage area. The criteria developed and listed below are divided into three categories, namely material, movement and method.

A study has been conducted in order to evaluate the impact of implementation changes on material handling management in the production department. The evaluation procedure is conducted based on evaluation criteria and sub-criteria that indicate significant change in implementation. Vieira, Pasa, Borsa, Milan, and Pandolfo (2011) summarized MHE implementation evolution success factors by four criteria shown as follows.

(1) Cost. Monetary value exists to support operation maintenance such as MHE expenditures used in terms of periodic maintenance. This criterion involves:

(a) mechanical shutdowns,

(b) electrical shutdowns,

(c) corrective painting.

(2) Safety in service. Identifies MHE operator's conduct regarding new handling and internal transport:

(a) safety in handling,

(b) tooling storage,

(c) efficient routing.

(3) Service reliability. Identifies manufacturing satisfaction level in terms of reliability:

(a) operator's autonomy,

(b) operator's performance and availability.

(4) Agility. Identifies the time spent due to MHE running with additional tool exchange handling

Table 1. The structure of the three major categories of evaluation criteria.

\begin{tabular}{|c|c|c|}
\hline (a) Cost & (b) Benefit & (c) Compatibility \\
\hline $\begin{array}{l}\text { (1) Purchase cost: } \\
\text { MHE cost } \\
\text { Installation cost } \\
\text { (2) Operation cost: } \\
\text { Labor cost } \\
\text { Energy cost } \\
\text { (3) Logistic support cost: } \\
\text { User training } \\
\text { Dismantling } \\
\text { Maintenance: spare cost, spare part holding } \\
\text { cost, repair labor cost, main-tenance training }\end{array}$ & $\begin{array}{l}\text { (1) Purchase benefits: } \\
\text { Guaranty } \\
\text { Payment modality } \\
\text { (2) Operation: } \\
\text { Operative flexibility } \\
\text { Reliability } \\
\text { Safety } \\
\text { User friendliness } \\
\text { Space } \\
\text { (3) Strategic flexibility } \\
\text { (4) Performance: velocity, load, accuracy, } \\
\text { service area }\end{array}$ & $\begin{array}{l}\text { (1) Workplace: } \\
\text { Size } \\
\text { Weight } \\
\text { (2) Equipment: } \\
\text { Displacement velocity } \\
\text { Space } \\
\text { Ancillary equipment } \\
\text { Structural adjustment }\end{array}$ \\
\hline
\end{tabular}


(discounting the times associated with the machine, such as loose and/or fix arrays or tools):
(a) setup agility,
(b) material handling quickness,
(c) tooling handling quickness.

\section{Multi-criteria decison making methods}

\subsection{Determining weight of criteria}

\subsubsection{Objective weights: entropy weights}

The concept of deriving the weights based on the entropy method is to appraise the weights without the direct involvement of the DMs. It admits that the importance of a criterion is a direct function of the information conveyed by it relative to the whole set of alternatives. Using entropy for determining weight is based on the idea that a criterion is more important if it creates a greater dissemination in the evaluations of the alternatives. The superiority of applying the entropy method for obtaining the weight of a criterion is that it avoids the subjectivity of DMs in determining the weight but includes the objective assessment instead, and it delivers an advantage when DMs conflict concerning the values of weights (Song, Minga, Wua, \& Zhua, 2013).

In this study, the objective weight is obtained by using the entropy method. The calculation of the objective weight of (sub-)criteria above an alternative level by using the entropy method can be summarized as follows.

\section{Step 1. Construct a decision matrix}

Consider that there are $m$ alternatives, $n$ evaluation criteria, and $k$ historical data. If the historical data indicate various values, the triangular fuzzy number of the data $(l, m, u)$ can be constructed by using the geometric mean method. The fuzzy value of the historical data corresponding to the $m$ alternatives versus the $n$ objective sub-criteria above the alternatives layer can be determined by using the following procedure:

$$
l=\min _{i}\left\{x_{i j}\right\} ; \quad m=\left(\prod_{i=1}^{k} x_{i}\right)^{l / k} ; \quad u=\min _{i}\left\{x_{i j}\right\} .
$$

\section{Step 2. Normalize a fuzzy decision matrix}

Dealing with the benefit criteria, of which the more the better, and the cost criteria, of which the fewer the better, the original fuzzy evaluation value $\tilde{x}_{i j}$ should be converted to a dimensionless index through normalization. The normalized fuzzy decision matrix is denoted by $\tilde{\boldsymbol{R}}$, which can be obtained from:

$$
\tilde{\boldsymbol{R}}=\left[\tilde{r}_{i j}\right]_{m \times n}, \quad i=1,2, \rightleftharpoons, m ; \quad j=1,2, \rightleftharpoons, n .
$$

The above formula can be calculated in detail as follows.

(1) For the above benefit sub-criteria alternatives layer:

$$
\left[\tilde{r}_{i j}\right]_{m \times n}=\left(\frac{l_{i j}}{U_{j}^{*}}, \frac{m_{i j}}{U_{j}^{*}}, \frac{u_{i j}}{U_{j}^{*}}\right)
$$

where $U_{j}^{*}=\max u_{i j}$.
(2) For the above cost sub-criteria alternatives layer:

$$
\left[\tilde{r}_{i j}\right]_{m \times n}=\left(\frac{l_{j}^{*}}{u_{i j}}, \frac{l_{j}^{*}}{m_{i j}}, \frac{l_{j}^{*}}{l_{i j}}\right)
$$

where $l_{j}^{*}=\min l_{i j}$.

The normalization method bounds the original fuzzy evaluation value between zero and one. After obtaining the fuzzy normalized decision matrix for each sub-criterion, the crisp value of the normalized weight is expressed by $r_{i j}$. The Center of Gravity (COG) method is applied to derive the crisp value of the fuzzy evaluation weight of subcriteria. Here, we can define

$$
R_{j}=\sum_{i=1}^{n} r_{i j}
$$

Step 3. Calculate the entropy value of each criterion

The entropy value of $E_{j}$ for each sub-criterion under the objective evaluation $j$ can be calculated by using the following formula:

$$
E_{j}=-k \sum_{i=1}^{n} p_{i j}=\ln p_{i j}-k \sum_{i=1}^{n} \frac{r_{i j}}{R_{j}} \ln \frac{r_{i j}}{R_{j}} .
$$

Step 4. Calculate the degree of diversification from the entropy value

The diversification degree $d_{j}=1-E_{j}, j=1,2, \rightleftharpoons, n$ represents the inherent contrast intensity of sub-criterion $j$. The higher the diversification degree, the more important is the criterion.

Step 5. Obtain the objective weight based on the entropy

The objective weight $w_{o j}$ of the jth sub-criterion above the alternative level can be calculated by using the equation

$w_{o j}=\frac{d_{j}}{\sum_{k=1}^{n} d_{j}}=\frac{1-E_{j}}{\sum_{i=k}^{n}\left(1-E_{j}\right)} ; \quad 0 \leq w_{o j} \leq 1, \sum_{i=1}^{n} w_{o j}=1$.

\subsubsection{Subjective weight: fuzzy AHP}

AHP, first introduced by Saaty (1980), is one of the decision making techniques that applies a pairwise comparison matrix to measure the relative importance of criteria. Since vagueness and uncertainty exist in DMs' opinions, the importance rating cannot be used to represent imprecise judgments. For improving DMs' opinions in a fuzzy environment, Laarhoven and Pedrycz (1983) proposed fuzzy AHP by adopting triangular fuzzy numbers, which refers to fuzzy set theory introduced by Zadeh (1965). Their study also clarified the comparison result of applying classical importance ratings and fuzzy triangular importance ratings to AHP. By referring to fuzzy logic, Triangular Fuzzy Numbers (TNFs) (Do, Chen, \& Hsieh, 2015; Feizizadeh, Roodposhti, Jankowski, \& Blaschke, 2014; Li, 2014; Shaverdi, Heshmatib, \& Ramezanic, 2014; Song, Zhu, Jia, \& He, 2014; Wang \& Wang, 2014) and trapezoidal fuzzy numbers (Buckley, 
Table 2. Triangular fuzzy numbers based on the Saaty's scale.

\begin{tabular}{lccccccccc}
\hline Fuzzy number & $\tilde{1}$ & $\tilde{2}$ & $\tilde{3}$ & $\tilde{4}$ & $\tilde{5}$ & $\tilde{6}$ & $\tilde{7}$ & $\tilde{8}$ & $\tilde{9}$ \\
\hline $\begin{array}{l}\text { Fuzzy triangular } \\
\text { number }\end{array}$ & $(1,1,1)$ & $(1,2,3)$ & $(1,3,5)$ & $(2,4,6)$ & $(3,5,7)$ & $(4,6,8)$ & $(5,7,9)$ & $(6,8,9)$ & $(7,9,9)$ \\
$\begin{array}{l}\text { Reciprocal fuzzy } \\
\text { triangular number }\end{array}$ & $(1,1,1)$ & $(1 / 3,1 / 2,1)$ & $(1 / 5,1 / 3,1)$ & $(1 / 6,1 / 4,1 / 2)$ & $(1 / 7,1 / 5,1 / 3)$ & $(1 / 8,1 / 6,1 / 4)$ & $(1 / 9,1 / 7,1 / 5)$ & $(1 / 9,1 / 8,1 / 6)$ & $(1 / 9,1 / 9,1 / 7)$ \\
\hline
\end{tabular}

1985; Cunbin \& Peng, 2012; Tian, Zheng, Zhu, Chen, \& Sun, 2012; Tolga \& Kahraman, 2008) are most often used to develop the importance ratings of classical AHP and incorporate a decision making process under vagueness and uncertainty.

In this study, fuzzy AHP is used to determine subjective weights for evaluation criteria through pairwise comparison. The procedures can be briefly explained by the following steps.

\section{Step 1. Define the problem}

The problem should be generalized clearly through defining what the main problem with respect to the objective, identifying criteria $(i=1,2, \ldots, n)$, sub-criteria $(l=1,2, \ldots, L)$, and alternatives $(m=1,2, \ldots, M)$ related to the problem. The DM should be determined whether it is single or multi DM. On the other hand, set the number of $k$-DMs $(k=1,2, \ldots, K)$.

Step 2. Construct the problem as a hierarchy

Step 3. For each $k$-DMs, construct a pairwise comparison matrix for criteria and sub-criteria by using Saaty's importance scale 1-9

Step 4. Perform a consistency test for each pairwise comparison matrix

Saaty (1980) suggested the maximal eigenvalue $\left(\lambda_{\max }\right)$ be used to evaluate the effectiveness of measurements.

Let $V$ denote an $n$-dimensional column vector indexing the sum of the weight values for the importance scale of criteria $(W)$, which can be determined by using the formula

$$
\begin{aligned}
V & =\left[v_{i}\right]_{n \times 1}=A \cdot W^{T}=\left[\begin{array}{cccc}
1 & a_{12} & \cdots & a_{1 n} \\
a_{21} & 1 & \cdots & a_{2 n} \\
\vdots & \vdots & \ddots & \vdots \\
a_{n 1} & a_{n 2} & \cdots & 1
\end{array}\right]\left[w_{1}, w_{2}, \ldots w_{n}\right] \\
& =\left[\begin{array}{c}
V_{1} \\
V_{2} \\
\ldots \\
V_{3}
\end{array}\right] ; i=1,2, \ldots, n
\end{aligned}
$$

Finally, $\lambda_{\max }$ can be determined by dropping those values into formula

$$
\lambda_{\max } \frac{\sum_{i=1}^{n} \frac{V_{i}}{W_{i}}}{n}, i=1,2, \ldots, n .
$$

To check consistency between pairwise comparison matrices, the Consistency Index (CI) and Consistency Ratio (CR) are estimated using the equations

$$
\mathrm{CI}=\frac{\lambda_{\max }-n}{n-1} \quad \text { and } \quad \mathrm{CR}=\frac{\mathrm{CI}}{\mathrm{RI}} \leq 0.1,
$$

where RI is a Random Index. If the value of CR is below 0.1 , it indicates that the comparison judgment in performing the importance scale does not consist of randomness and, in other words, the evaluation of the importance degrees is acceptable and reasonable.

Step 5. Transform the pairwise comparison matrix into a Triangular Fuzzy Number (TNF) according to Table 2

Step 6. Aggregate the elements of the synthetic fuzzy pairwise comparison matrix for criteria $\left(\tilde{a}_{i j}\right)$ and subcriteria $\left(\tilde{a}_{l j}\right)$ judged by K-DMs by using the geometric mean method suggested by Buckley (1985)

The TNF can be denoted by $\tilde{a}=(l, m, u)$. The operational rule of TFN $\tilde{a}_{1}=\left(l_{1}, m_{1}, u_{1}\right)$ and $\tilde{a}_{2}=$ $\left(l_{2}, m_{2}, u_{2}\right)$ are summarized in Table 3.

$$
\begin{aligned}
\tilde{a}_{i j} & =\left(\tilde{a}_{i j k} \otimes \cdots \otimes \tilde{a}_{i j 3} \otimes \cdots \otimes \tilde{a}_{i j K}\right)^{1 / \mathrm{K}} \\
\tilde{a}_{l j} & =\left(\tilde{a}_{l j k} \otimes \cdots \otimes \tilde{a}_{l j 3} \otimes \cdots \otimes \tilde{a}_{l j K}\right)^{1 / \mathrm{K}} \\
\tilde{a}_{m j} & =\left(\tilde{a}_{m j k} \otimes \cdots \otimes \tilde{a}_{m j 3} \otimes \cdots \otimes \tilde{a}_{m j K}\right)^{1 / \mathrm{K}}
\end{aligned}
$$

Step 7. Calculate fuzzy weight for each criterion $\left(\tilde{w}_{i}\right)$ and sub-criterion $\left(\tilde{w}_{l}\right)$

$$
\begin{aligned}
& \tilde{w}_{i}=\tilde{r}_{i} \varnothing\left[\tilde{r}_{1} \oplus \cdots \oplus \tilde{r}_{i} \oplus \cdots \oplus \tilde{r}_{n}\right] \\
& \tilde{w}_{l}=\tilde{r}_{l} \varnothing\left[\tilde{r}_{l} \oplus \cdots \oplus \tilde{r}_{l} \oplus \cdots \oplus \tilde{r}_{L}\right]
\end{aligned},
$$

where

$$
\begin{aligned}
& \tilde{r}_{i}=\left(\tilde{a}_{i 1} \otimes \cdots \otimes \tilde{a}_{i j} \otimes \cdots \otimes \tilde{a}_{i n}\right)^{1 / n} \\
& \tilde{r}_{i}=\left(\tilde{a}_{l 1} \otimes \cdots \otimes \tilde{a}_{l j} \otimes \cdots \otimes \tilde{a}_{l n}\right)^{1 / L}
\end{aligned}
$$

Table 3. The algebraic operations of any two fuzzy numbers $\tilde{a}_{1}$ and $\tilde{a}_{2}$.

\begin{tabular}{lll}
\hline Fuzzy operation & Fuzzy formula & Calculation \\
\hline Fuzzy addition & $\tilde{a}_{1} \oplus \tilde{a}_{2}=\left(\mathrm{l}_{1}, \mathrm{~m}_{1}, \mathrm{u}_{1}\right) \oplus\left(\mathrm{l}_{2}, \mathrm{~m}_{2}, \mathrm{u}_{2}\right)$ & $\left(\mathrm{l}_{1}+\mathrm{l}_{2}, \mathrm{~m}_{1}+\mathrm{m}_{2}, \mathrm{u}_{1}+\mathrm{u}_{2}\right)$ \\
Fuzzy subtraction & $\tilde{a}_{1} \ominus \tilde{a}_{2}=\left(\mathrm{l}_{1}, \mathrm{~m}_{1}, \mathrm{u}_{1}\right) \ominus\left(\mathrm{l}_{2}, \mathrm{~m}_{2}, \mathrm{u}_{2}\right)$ & $\left(l_{1}-\mathrm{u}_{2}, \mathrm{~m}_{1}-\mathrm{m}_{2}, \mathrm{u}_{1}-\mathrm{l}_{2}\right)$ \\
Fuzzy multiplication & $\tilde{a}_{1} \otimes \tilde{a}_{2}=\left(l_{1}, \mathrm{~m}_{1}, \mathrm{u}_{1}\right) \otimes\left(\mathrm{l}_{2}, \mathrm{~m}_{2}, \mathrm{u}_{2}\right)$ & $\left(l_{1} \cdot \mathrm{l}_{2}, \mathrm{~m}_{1} \cdot \mathrm{m}_{2}, \mathrm{u}_{1} \cdot \mathrm{u}_{2}\right)$ \\
Fuzzy division & $\tilde{a}_{1} \oslash \tilde{a}_{2}=\left(l_{1}, \mathrm{~m}_{1}, \mathrm{u}_{1}\right) \oslash\left(\mathrm{l}_{2}, \mathrm{~m}_{2}, \mathrm{u}_{2}\right)$ & $\left(1_{1} / \mathrm{u}_{2}, \mathrm{~m}_{1} / \mathrm{m}_{2}, \mathrm{u}_{1} / \mathrm{l}_{2}\right)$ \\
\hline
\end{tabular}


Step 8. Obtain the crisp values of criteria $\left(w_{i}\right)$ and sub-criteria $\left(w_{l}\right)$ weights to find out the importance order based on the crisp values from large to small

The COG is introduced to derive a crisp value in view of simplicity and efficiency (Pan, 2008). The COG formula can be expressed as follows:

$$
Z^{*}=\frac{\int \mu(Z) \cdot Z \mathrm{~d} z}{\mu(Z) \mathrm{d} z}
$$

where $\mu(Z)$ is the membership value and $Z^{*}$ is the weighted average.

Step 9. Compute the global weight of each subcriterion $\left(W_{j}\right)$

$$
\begin{aligned}
W_{j} & =w_{i} \otimes w_{l} ; \quad l=1,2, \ldots, L ; \quad i=1,2, \ldots, n ; \\
j & =1,2, \ldots, L
\end{aligned}
$$

\subsubsection{Integration of (subjective and objective) weight}

In order to take notice of the importance of criteria and consider the experience of the DMs, it is essential to integrate the subjective weight from the DMs' judgment and the objective weight obtained from the entropy weight. The integration aims to gain a comprehensive determination of criteria weight. To affirm the difference risk among the criteria, the objective and subjective weights are integrated by using the multiplication approach, which is derived through multiplying the objective entropy weight by the subjective weight and then normalizing the value.

The procedure of integrating the weight can be written as follows (Ding, 2011):

$$
W_{j}=\frac{w_{s j} x w_{o j}}{\sum_{j=1}^{n} w_{s j} x w_{o j}} x \sum_{j=1}^{n} w_{s j}, \quad j=1,2, \rightleftharpoons, L,
$$

where $w_{\mathrm{s} j}$ is the subjective weight of the $j$ th sub-criterion obtained by the DMs' judgment, $w_{\mathrm{o} j}$ is the objective weight of the $j$ th sub-criterion obtained by the entropy method, and $W_{j}$ is the integrated weight of the $j$ th sub-criterion.

\subsection{Hierarchical fuzzy TOPSIS}

Hwang and Yoon (1981) proposed the technique for order preference by similarity to an ideal solution (TOPSIS). In TOPIS, the best alternative is selected according to the one which indicates farthest distance from Negative Ideal Solution (NIS) or in other words the one which indicates shortest distance from Positive Ideal Solution (PIS). In the environment under uncertainty and vagueness, TOPSIS is combined with fuzzy theory for carrying out the opinion of DM into fuzzy preferences. Several studies in terms of decision making and performance evaluation have been conducted by applying fuzzy TOPSIS to solve the problem under uncertain environment. Some of them developed TOPSIS by transforming the importance scale into triangular fuzzy number (Ertugrul \& Oztas, 2014; Kumar \& Joshi, 2014; Li \& Ye, 2014; Wang, Chan, \& Li, 2015) and into trapezoidal fuzzy number (Mohammadi, Mohammadi, Mohammadi, \& Mohammadi, 2011; Xu \& Zhang, 2015; Yazdian \& Shahanaghi, 2009). TOPSIS was combined with another method since the evaluation of the problem is more complex and the comprehensive decision is required. Past studies adopted TOPSIS integrated with another method under a fuzzy environment such as the Analytic Network Process (ANP) (Mohaghar, Fathi, Faghih, \& Turkayesh 2012; Önüt, Kara, \& Isik, 2009; Shemshadi, Toreihi, Shirazi, \& Tarokh, 2011), multichoice goal programming (MCGP) (Erdebilli \& Saputro, 2014), AHP (Akman \& Baynal, 2014; Ballı \& Korukoğlu, 2009; Kutlu \& Ekmekçioğlu, 2012; Sun, 2010; Taylan, Bafail, Abdulaal, \& Kabli 2014), or MOMILP (Jadidi, Hong, Firouzi, Yusuff, \& Zulkifli, 2008).

To deal with alternatives selection, fuzzy TOPSIS is adopted. In this study, the weights of the evaluation criteria are derived from fuzzy AHP. The steps of hierarchical fuzzy TOPSIS can be described in detail as follows.

(3) Generating feasible alternatives, determining the evaluation criteria, and setting up a group of Decision Makers (DMs). Assume that there are $m$ alternatives, $L$ evaluation criteria and $k$ DMs.

(4) Obtain the global weights of the sub-criteria $\left(W_{j}\right)$ (under the corresponding $i$ th criterion) by using fuzzy AHP.

(5) Choose the appropriate linguistic ratings for alternatives with respect to criteria $\left(\tilde{x}_{i j}\right)$ as TFN.

(6) Obtain the aggregated fuzzy rating $\tilde{x}_{i j}$ of alternative $A_{i}$ under sub-criterion $C_{j}$ (under the corresponding $i$ th criterion) evaluated by $k$ experts:

$$
\begin{aligned}
\tilde{x}_{i j} & =\frac{1}{k}\left[\tilde{x}_{i j}^{1}+\tilde{x}_{i j}^{2}+\cdots \tilde{x}_{i j}^{k}\right] ; \quad i=1,2, \ldots, m ; \\
j & =1,2, \ldots, L .
\end{aligned}
$$

(7) Construct the fuzzy decision matrix

$$
\begin{aligned}
& \begin{array}{llll}
S C_{1} & S C_{2} & \cdots & S C_{L}
\end{array} \\
& \tilde{D}=\begin{array}{c}
A_{1} \\
A_{2} \\
\vdots \\
A_{m}
\end{array}\left[\begin{array}{cccc}
\tilde{x}_{11} & \tilde{x}_{12} & \cdots & \tilde{x}_{1 L} \\
\tilde{x}_{21} & \tilde{x}_{22} & \cdots & \tilde{x}_{2 L} \\
\vdots & \vdots & \vdots & \vdots \\
\tilde{x}_{m 1} & \tilde{x}_{m 2} & \cdots & \tilde{x}_{m L}
\end{array}\right] ; \quad i=1,2, \ldots, m ; \\
& j=1,2, \ldots, L \text {. }
\end{aligned}
$$

(8) Normalize the fuzzy decision matrix.

The normalized fuzzy decision matrix denoted by $\tilde{R}$ is obtained by the following formula:

$$
\tilde{\mathrm{R}}=\left[\tilde{r}_{i j}\right]_{m \times L}, \quad i=1,2, \ldots, m ; \quad j=1,2, \ldots, L .
$$


The above formula can be calculated in detail as:

(a) for the above benefit sub-criteria alternatives layer

$$
\tilde{r}_{i j}=\left(\frac{l_{i j}}{U_{j}^{*}}, \frac{m_{i j}}{U_{j}^{*}}, \frac{u_{i j}}{U_{j}^{*}}\right),
$$

where $U_{j}^{*}=\max u_{i j}$;

(b) for the above cost sub-criteria alternatives layer

$$
\tilde{r}_{i j}=\left(\frac{l_{j}^{*}}{u_{i j}}, \frac{l_{j}^{*}}{m_{i j}}, \frac{l_{j}^{*}}{l_{i j}}\right),
$$

where $l_{j}^{*}=\min l_{i j}$.

(9) Construct the weighted normalized fuzzy decision matrix.

According to the different importance of each criterion, we can construct the weighted normalized fuzzy decision matrix as

$$
\tilde{V}=\left[\tilde{v}_{i j}\right]_{m \times L}, \quad i=1,2, \ldots, m ; \quad j=1,2, \ldots, L,
$$

where $\tilde{v}_{i j}=\tilde{r}_{i j} \otimes W_{j,} i=1,2, \ldots, m ; j=1,2, \ldots, L$ and $W_{j}$ is the global weight of sub-criterion $j$.

The weights of the above subjective and objective subcriteria of the alternatives layer are obtained by using a different method. The subjective weight is obtained by using fuzzy AHP and the objective weight is obtained by using the entropy method. Because the problem contains two different weight categories, we have to be clear about the conditions in which the weight is derived and whether it should be applied. To deal with these conditions, the following cases need to be considered.

\section{(10) Condition I}

If the problem consists of only subjective (sub-) criteria, then use the fuzzy AHP approach to obtain the weight $\left(W_{j}\right)$.

\section{(11) Condition II}

If the problem consists of only objective (sub-)criteria, then use the entropy weighting method $\left(W_{j}\right)$.

\section{(12) Condition III}

If the problem consists of both objective and subjective sub-criteria, then use the integration weight $\left(W_{j}\right)$.

(13) Determine the fuzzy positive-ideal solution (FPIS) $\mathrm{S}^{+}$and fuzzy negative-ideal solution (FNIS) $\mathrm{S}^{-}$. The formula can be obtained as follows:

$$
\begin{aligned}
S^{+} & =\left(\tilde{v}_{1}^{+}, \tilde{v}_{2}^{+}, \ldots, \tilde{v}_{L}^{+}\right) \\
S^{-} & =\left(\tilde{v}_{1}^{-}, \tilde{v}_{2}^{-}, \ldots, \tilde{v}_{L}^{-}\right),
\end{aligned}
$$

where $\tilde{v}_{j}^{+}=\max \left\{v_{i j 3}\right\}$ and $\tilde{v}_{j}^{-}=\min \left\{v_{i j 1}\right\}$ since $\tilde{v}_{j}$ are weighted normalized TFNs, $i=1,2, \ldots, m ; j=1,2, \ldots, L$.
(14) Calculate the distance of each alternative from FPIS $\left(d^{+}\right)$and FNIS $\left(d^{-}\right)$.

According to the vertex method, the distance between two triangular fuzzy numbers $\mathrm{A}_{1}\left(l_{1}, m_{1}, u_{1}\right)$ and $\mathrm{A}_{2}\left(l_{2}, m_{2}, u_{2}\right)$ is calculated as

$$
\begin{aligned}
\mathrm{d}\left(\mathrm{A}_{1}, \mathrm{~A}_{2}\right) & =\sqrt{\frac{1}{3}\left[\left(l_{1}-l_{2}\right)^{2}+\left(m_{1}-m_{2}\right)^{2}+\left(u_{1}-u_{2}\right)^{2}\right]} \\
d_{i}^{+} & =\sum_{j=1}^{n} d\left(\tilde{v}_{i j}, \tilde{v}_{j}^{+}\right), \quad i=1,2, \ldots, m \\
d_{i}^{-} & =\sum_{j=1}^{n} d\left(\tilde{v}_{i j}, \tilde{v}_{j}^{-}\right), \quad i=1,2, \ldots, m .
\end{aligned}
$$

(15) Calculate the Closeness Coefficient $\left(\mathrm{CC}_{i}\right)$ and rank the order of alternatives according to the coefficient.

After obtaining the distances $d^{+}$and $d^{-}$, we calculate the closeness coefficient of each alternative using the following formula

$$
C C_{i}=\frac{d_{i}^{-}}{d_{i}^{+}+d_{i}^{-}}, \quad i=1,2, \ldots, m .
$$

Based on the value of the closeness coefficient of each alternative, we determine the ranking order of all alternatives from the highest closeness coefficient to the lowest. The alternative with the highest closeness coefficient is the best choice.

\section{Augmented $\varepsilon$-constraint method}

The augmented $\varepsilon$-constraint method, known as AUGMECON, was developed by Mavrotas (2009). The method was proposed to improve the implementation of the $\epsilon-$ constraint method in multi-objective optimization. The traditional $\epsilon$-constraint method was originally introduced by Chankong and Haimes (1983).

To illustrate the transformation of the augmented $\epsilon$ constraint method, let us consider a set of multi-objective problems based on the original $\epsilon$-constraint formula by supposing that there are $n$ objective functions. In brief, we have problem $P\left(e_{j}\right)$ as follows:

$$
\begin{gathered}
\operatorname{Min} f_{j}(x),\left\{f_{1}(x), f_{2}(x), \ldots, f_{n}(x)\right\} \\
\text { s.t. } \quad f_{i}(x) \leq e_{i}, \forall i \in \frac{\{1,2, \ldots, n\}}{\{j\}}, \\
x \in S
\end{gathered}
$$

where $x$ represents a set of decision variables, $f_{1}(x)$, $f_{2}(x), \ldots, f_{n}(x)$ are objectives functions, and the feasible region is shown by $S$.

According to the $\epsilon$-constraint method, we are interested in one among the existing objective functions is to be prioritized for optimization and the remaining objective functions are to be added to the constraints. For example, we would like to minimize $f_{1}(x)$ as an objective 
function. The problem $P\left(e_{1}\right)$ can be written as follows:

$$
\begin{array}{ll}
\text { Min } & f_{1}(x) \\
\text { s.t. } & f_{2}(x) \leq e 2 \\
& f_{3}(x) \leq e_{3} \\
& \vdots \\
& f_{n}(x) \leq e_{n} \\
& x \in S
\end{array}
$$

The obtained optimal solution of problem $P\left(e_{1}\right)$ is not literally efficient, but it is a weakly efficient solution and can be achieved only if all the $(n-1)$ objective function constraints are binding (Ehrgott \& Wiecek, 2005; Miettinen, 1998). Therefore, equality transformation of objective function constraints must be done by adding slack $\left(s_{1}\right)$ (for the maximization problem) or surplus $\left(s_{\mathrm{p}}\right)$ (for the minimization problem) for the following order of objective function constraints at the same time. Thus, the problem $P\left(e_{1}\right)$ is transformed to become

$$
\begin{array}{cl}
\operatorname{Min} & \left(f_{1}(x)+e p s\left(\frac{s p_{2}}{r_{2}}+\frac{s p_{3}}{r_{3}}+\cdots+\frac{s_{p n}}{r_{n}}\right)\right) \\
\text { s.t. } & f_{2}(x)+s p_{2}=e_{2} \\
& f_{3}(x)+s p_{2}=e_{3} \\
\vdots \\
\\
\quad f_{n}(x)+s_{p n}=e_{n} \\
x \in S \text { and } s_{i} \in R^{-}
\end{array}
$$

where eps is a small number (usually between $10^{-3}$ and $\left.10^{-6}\right) ; s_{i}$ in the second term of the objective function will be replaced by $s_{i} / r_{i}$ in order to avoid any scaling problems, where $r_{i}$ is the range of the $i$ th objective function, which is calculated from the payoff table. Finally, the problem is entirely transformed into augmented $\varepsilon$-constraint in the following:

$$
\begin{array}{cl}
\operatorname{Min} & \left(f_{1}(x)+e p s\left(\frac{s p_{2}}{r_{2}}+\frac{s p_{3}}{r_{3}}+\cdots+\frac{s_{p n}}{r_{n}}\right)\right) \\
\text { s.t. } & f_{2}(x)+s_{p 2}=e_{2} \\
& f_{3}(x)+s p_{3}=e_{3} \\
& \vdots \\
& f_{n}(x)+s_{p n}=e_{n} \\
& x \in S \text { and } s_{i} \in R^{-}
\end{array}
$$

\section{Developing the optimization model for MHE selection}

We develop MOMILP according to a real case adapted from a manufacturer where it applies in specific circumstances as follows.

(1) The MHE selection problem is highlighted at an intermediate level, in particular for an industrial truck.
(2) The MHE is focused on warehouse operation.

(3) The materials handled are a single product.

(4) The permissible load for MHE is regulated by the warehouse authority because the product is perishable. On the other hand, in order to handle product safely, the maximum load should respect the authority rather than the load capacity of the MHE itself.

(5) The notation defined to formulate the model is as follows.

Indices:

$i=1,2, \ldots, n$ are the indices for the MHE.

Parameters:

$\mathrm{MC}_{i} \quad$ Maintenance cost of MHE $i$ per day

$\mathrm{OC}_{i} \quad$ Operation cost of MHE $i$ per minute

$P_{i} \quad$ Purchase cost of MHE $i$

$S_{i} \quad$ Savage value of MHE $i$ in the expected life year

$F_{i} \quad$ Expected life of MHE $i$

$D_{\text {store }} \quad$ Average of product received in warehouse (per day)

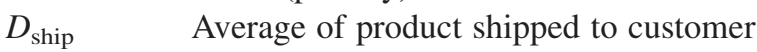
(per day)

$E_{i} \quad$ Maximum load capacity of MHE $i(\mathrm{~kg})$

$E_{\max } \quad$ Permissible load (kg)

LULT $_{\text {store }, i}$ Loading/unloading time per move of received product using MHE $i$ (min)

LULT $_{\text {ship }, i} \quad$ Loading/unloading time per move of delivered product using MHE $i$ (min)

$T_{\text {store }, i} \quad$ Travel time per trip of received product with load using MHE $i$ to storage area (min)

$T_{\text {ship } i} \quad$ Travel time per trip of delivered product with load using MHE $i$ to shipping area (min)

$t_{\text {store }, i} \quad$ Travel time per trip of received product without load using MHE $i$ to receiving area (min)

$t_{\text {ship }, i} \quad$ Travel time per trip of delivered-product without load using MHE $i$ to storage area (min)

$\mathrm{CC}_{i} \quad$ MHE $i$ rating ( $=$ closeness coefficient obtained from entropy based hierarchical fuzzy TOPSIS)

$h_{i} \quad$ Lift height of MHE $i$ (metre)

$H_{i} \quad$ Body height of MHE $i$ (metre)

$b_{i} \quad$ Width of MHE $i$ with load (metre)

$H_{\text {storage } \quad \text { Height of storage (metre) }}$

$L \quad$ Width of aisle (metre)

TH Total available work hour per day (min)

$A_{\text {st }, i} \quad$ Aisle for $90^{\circ}$ stacking (metre)

$U \quad$ Utility of time

Decision variables:

$$
Y_{i}= \begin{cases}1, & \text { if MHE } i \text { is selected } \\ 0, & \text { otherwise }\end{cases}
$$

$X_{i}=$ Number of MHE $i$ (unit) 
Objective functions:

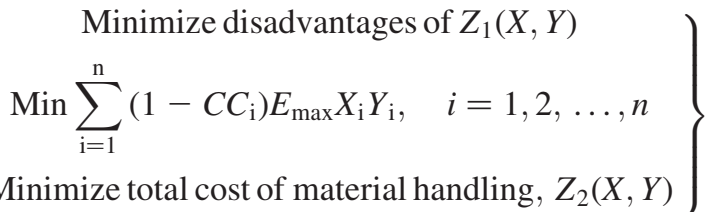

$$
\begin{aligned}
& \operatorname{Min} \sum_{i-1}^{n} X_{i} \cdot Y_{i}\left[\left(\frac{P_{i}-S_{i}}{F_{i}}\right)+\mathrm{MC}_{i}\right] \\
& +\sum_{i=1}^{n}\left(\begin{array}{c}
D_{\text {store }} \cdot\left(\mathrm{LULT}_{\text {store }, i}+T_{\text {store }, i}+t_{\text {store }, i}\right) \\
+D_{\text {ship }} \cdot\left(\mathrm{LULT}_{\text {ship }, i}+T_{\text {ship }, i}+t_{\text {ship }, i}\right) \\
X_{i} E_{\text {max }}
\end{array}\right) \\
& \quad \times \mathrm{OC}_{i} \cdot Y_{i}, i=1,2, \ldots, n
\end{aligned}
$$

Objective function (1) aims to minimize the disadvantage of material handling operation $\left(1-\mathrm{CC}_{i}\right)$ from the selected MHE. On the other hand, this objective function ensures the achievement of the maximum value of disadvantage of material handling operation $\left(\mathrm{CC}_{i}\right)$ from the selected MHE. The disadvantage of material handling operation are measured involving some tangible and intangible criteria. In order to incorporate this objective, an alternative rating $\left(\mathrm{CC}_{i}\right)$ derived from the TOPSIS method is constructed in the model so that the selected MHE can contribute some benefits with respect to all loaded material during the handling operation. Objective function (2) guarantees that the selected MHE can provide the minimum total cost for material handling. Cost parameters involve depreciation cost, maintenance cost and operation cost (fuel/energy and labour cost). The depreciation cost is calculated by using a straight line method, which can be expressed as follows.

$$
\begin{aligned}
\text { Depreciation cost of MHE } & =\frac{\text { Purchase cost }- \text { Salvage value }}{\text { Expected life }} \\
& =\frac{P_{i}-S_{i}}{F_{i}}
\end{aligned}
$$

.Constraints:

$$
\begin{gathered}
\sum_{i=1}^{n} Y_{i}=1, \quad i=1,2, \ldots, n \\
\mathrm{U} \cdot \mathrm{TH} \leq \sum_{i=1}^{n} Y_{i}\left(\begin{array}{l}
D_{\text {store }} \cdot\left(\mathrm{LULT}_{\text {store }, i}+T_{\text {store }, i}+t_{\text {store }, i}\right) \\
+D_{\text {ship }} \cdot\left(\mathrm{LULT}_{\text {ship }, i}+T_{\text {ship }, i}+t_{\text {ship }, i}\right) \\
X_{i} E_{\text {max }}
\end{array}\right) \\
\leq \mathrm{TH}, i=1,2, \ldots, n \\
\sum_{i=1}^{n} Y_{i} \cdot h_{i} \geq \mathrm{H}_{\text {storage }}, \quad i=1,2, \ldots, n \\
\sum_{i=1}^{n} Y_{i} \cdot b_{i} \leq L, \quad i=1,2, \ldots, n
\end{gathered}
$$

$$
\begin{gathered}
\sum_{i=1}^{n} Y_{i} \cdot E_{i} \geq E_{\max }, \quad i=1,2, \ldots, n \\
\sum_{i=1}^{n} Y_{i} \cdot A_{\mathrm{st} i} \leq L, \quad i=1,2, \ldots, n .
\end{gathered}
$$

Constraint (3) allows only one MHE to be selected. Constraint (4) describes the number of selected MHEs should be appropriately determined so that it can fulfil the material handling operation within the available working hour per day and avoid a high number of idle MHEs. The number of idle and busy MHEs should be balanced in order to offer optimum utilization. Constraints (5), (6) and (8) ensure the flexibility and compatibility of selected MHEs in view of warehouse space. Constraint (5) ensures the lift height of an MHE is able to reach the maximum storage height when picking or storing the material. Constraint (6) ensures an MHE is able to travel through the aisle. Constraint (7) is to ensure that an MHE is able to load material up to the maximum weight allowed by the warehouse authority. Constraint (8) is intended to deal with the bound on the turning radius $\left(W_{a}\right)$ of an MHE between the storage aisles. The turning radius $\left(W_{a}\right)$ is one of the parameters considered in order to produce convenient movement when stacking is performed between the aisles. In general, stacking is performed at $90^{\circ}$ right turn angle. Constraint (8) ensures that the required aisle for stacking meets the available aisle. The aisle for $90^{\circ}$ stacking may vary depending on the industrial truck type. For common industrial trucks, the stacking aisle can be calculated as follows.

Pallet truck and low level order picker (Figure 1):

$$
A_{s t}=W_{a}-x+l_{6}+a .
$$

Pallet stackers and reach trucks - reach in (Figure 2):

$$
\mathrm{A}_{\mathrm{st}}=W_{a}+\sqrt{\left(l_{6}-x\right)^{2}+\left(\frac{b_{12}}{2}\right)^{2}}+a .
$$

Counterbalance trucks (E) - three-wheeled, close coupled steer or combi axle, reach trucks $(\mathrm{R})$ - reach out (Figure 3):

$$
\mathrm{A}_{\mathrm{st}}=W_{a}+\sqrt{\left(l_{6}+x\right)^{2}+\left(\frac{b_{12}}{2}\right)^{2}}+a .
$$

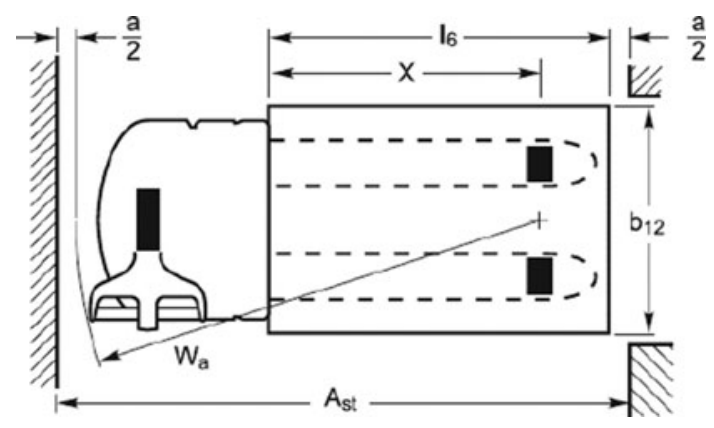

Figure 1. Dimensions of pallet truck and low level order picker. 


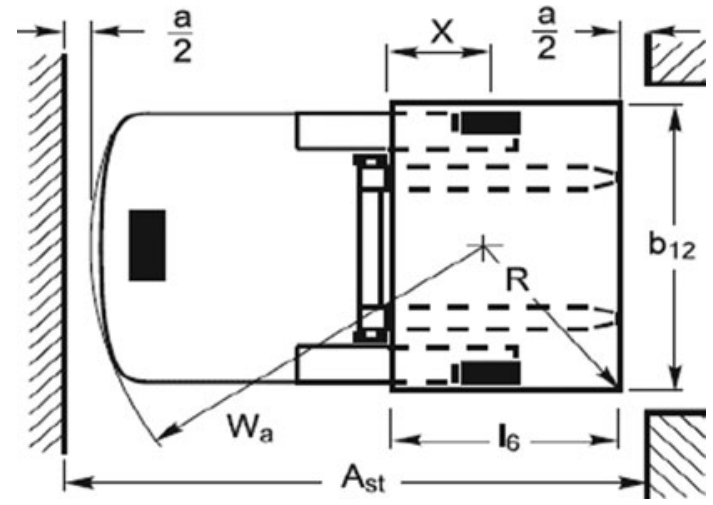

Figure 2. Dimensions of pallet stackers and reach trucks.

Counterbalance trucks ( $\mathrm{E}$ and $\mathrm{H})$ - four-wheeled with standard load $\left(b_{12} / 2 \leq \mathrm{b}_{13}\right)$ (Figure 4$)$ :

$$
A_{s t}=W_{a}+x+l_{6}+a .
$$

Counterbalance trucks ( $\mathrm{E}$ and $\mathrm{H})$ - four-wheeled with wide load $\left(b_{12} / 2>\mathrm{b}_{13}\right)$ (Figure 5$)$ :

$$
\mathrm{A}_{\mathrm{st}}=W_{a}+\sqrt{\left(l_{6}+x\right)^{2}+\left(\frac{b_{12}}{2}-b_{13}\right)^{2}}+a,
$$

where

$$
\begin{array}{ll}
A_{\mathrm{st}}=90^{\circ} \text { stacking aisle } & b_{12}=\text { load width } \\
W_{a}=\text { turning radius } & b_{13}=\text { minimum pivoting point } \\
& \text { distance } \\
R=\text { load radius } & x=\text { axle centre to fork face } \\
l_{6}=\text { load length } & a=\text { operating clearance } \\
& (200 \mathrm{~mm}) .
\end{array}
$$

Non-negativity and binary constraints:

$$
\begin{gathered}
X_{i} \geq 0 \quad \text { and integer, } \quad i=1,2, \ldots, n \\
Y_{i}=0 \text { or } 1, \quad i=1,2, \ldots, n
\end{gathered}
$$

Constraint (9) is set to ensure a positive and integer value for the number of MHEs. Constraint (10) is to deal with the decision of whether MHE $i$ is selected or not.

\section{Methodology}

The MHE selection problem is solved by using a hybrid method that is an integration of entropy based hierarchical fuzzy TOPSIS and MOMILP. The hybrid method is

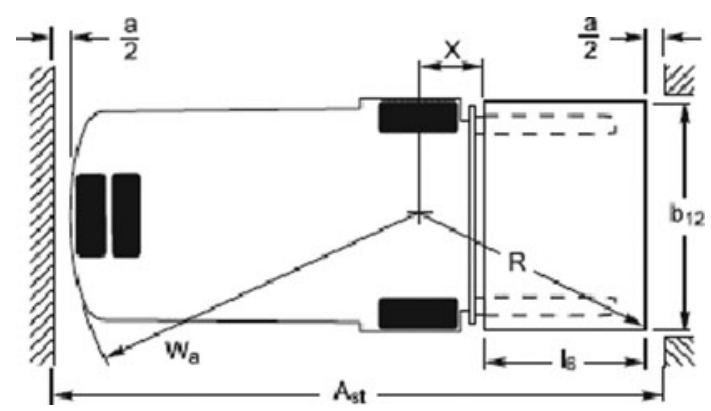

Figure 3. Dimensions of counterbalanced trucks (E) - threewheeled.

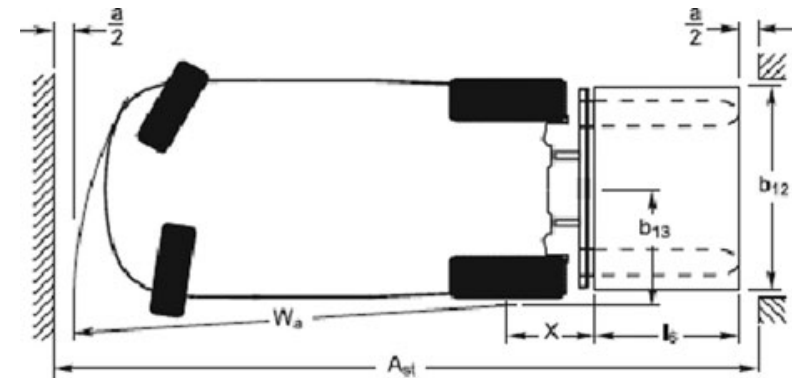

Figure 4. Dimensions of counterbalanced trucks (E and $\mathrm{H})-$ four-wheeled.

proposed to bring about comprehensive decision making in order to find the best MHEs for warehouse operations. To carry out procedures systematically in this method, the methodology is described briefly in Figure 6.

\section{Case study}

PLI, an affiliated manufacturing company, is a leading manufacturer in energy saving lighting. The main products are straight-tube fluorescent lamps and glass components. This issue is focused on the warehouse operation of finished-good product. Product meeting standard quality criteria will be placed in the transfer area before being either stored in the warehouse or shipped to customers. The problem aims to find an appropriate industrial truck to be used for loading, unloading and transporting product to storage racks and the shipping area.

The instructions guide the operator to handle the product in a safe way using an industrial truck, and they must be carried out appropriately. They deal with the following points: (1) product must be put down on the pallet before being loaded, (2) the industrial truck is allowed to load a maximum of two pallets at the same time due to the product's perishability.

\section{First stage}

We finally assemble five alternative industrial trucks, four criteria $\left(\mathrm{C}_{1}, \mathrm{C}_{2}, \mathrm{C}_{3}, \mathrm{C}_{4}\right)$ and 16 sub-criteria $\left(\mathrm{SC}_{1}, \mathrm{SC}_{2}\right.$, $\mathrm{SC}_{3}, \mathrm{SC}_{4}, \mathrm{SC}_{5}, \mathrm{SC}_{6}, \mathrm{SC}_{7}, \mathrm{SC}_{8}, \mathrm{SC}_{9}, \mathrm{SC}_{10}, \mathrm{SC}_{11}, \mathrm{SC}_{12}$, $\mathrm{SC}_{13}, \mathrm{SC}_{14}, \mathrm{SC}_{15}, \mathrm{SC}_{16}$ ) according to the literature and DMs' knowledge (see Figure 7). The alternatives, namely IC counterbalanced $\left(A_{1}\right)$, E-counterbalanced $\left(A_{2}\right)$, pallet truck $\left(\mathrm{A}_{3}\right)$, reach truck $\left(\mathrm{A}_{4}\right)$, and order picker $\left(\mathrm{A}_{5}\right)$ are evaluated under sub-criteria. The appraisal of criteria and sub-criteria weights and alternatives using TFN linguistic variables will be performed by three DMs having

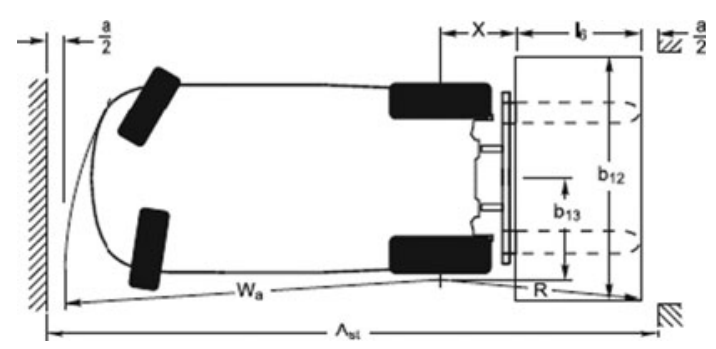

Figure 5. Dimensions of counterbalanced trucks (E and $\mathrm{H})-$ four-wheeled. 


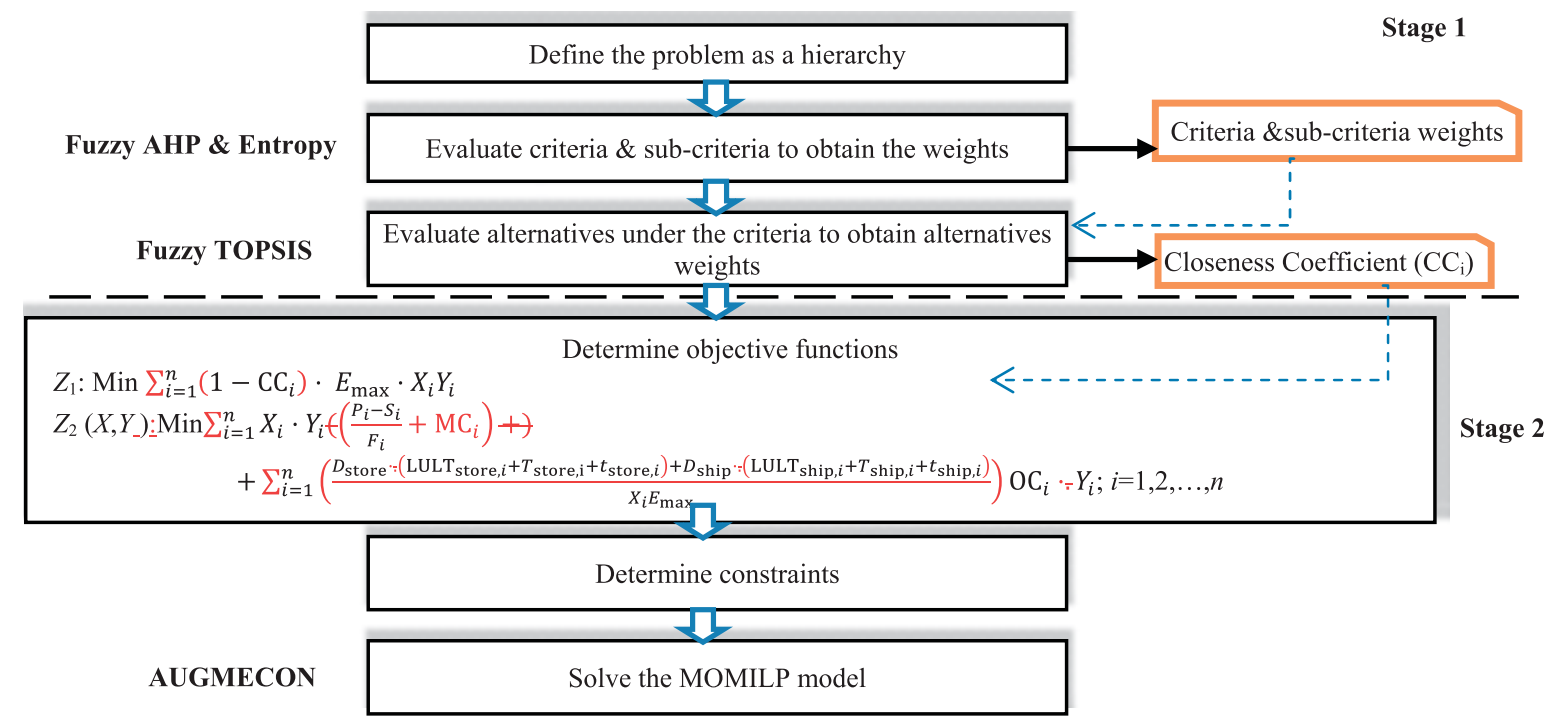

Figure 6. Methodology of the MHE selection problem.

warehouse expertise, including two warehouse supervisors and a senior operator. The alternative ratings judged by DMs in Table 4 refer to the linguistic variables in Table 8.

Generally, an industrial truck can run at a range of speeds, load capacity and lift height, such as the data provided in Table 5. In order to measure the essence of the data provided (in Table 5), the entropy method is proposed to determine the objective weights of sub-criteria, particularly for speed, load capacity and lift height. The subjective weight is obtained by using fuzzy AHP and the results are shown in Table 6.
In this case, we utilize the integration of objective and subjective weights for particular sub-criteria. Initially, sub-criteria, objective weights, and integrated weights of speed, load capacity and lift height are denoted by $\mathrm{SC}_{6}-$ $\mathrm{SC}_{8}-\mathrm{SC}_{9}, w_{06^{-}} w_{08^{-}} w_{09}$ and $W_{6}-W_{8}-W_{9}$. Finally, the objective weights are calculated as follows:

$$
\begin{aligned}
& \mathrm{w}_{\mathrm{o} 6}=\frac{0.0147}{0.0147+0.0463+0.0045}=0.224 \\
& \mathrm{w}_{\mathrm{o} 8}=\frac{0.0463}{0.0147+0.0463+0.0045}=0.707
\end{aligned}
$$

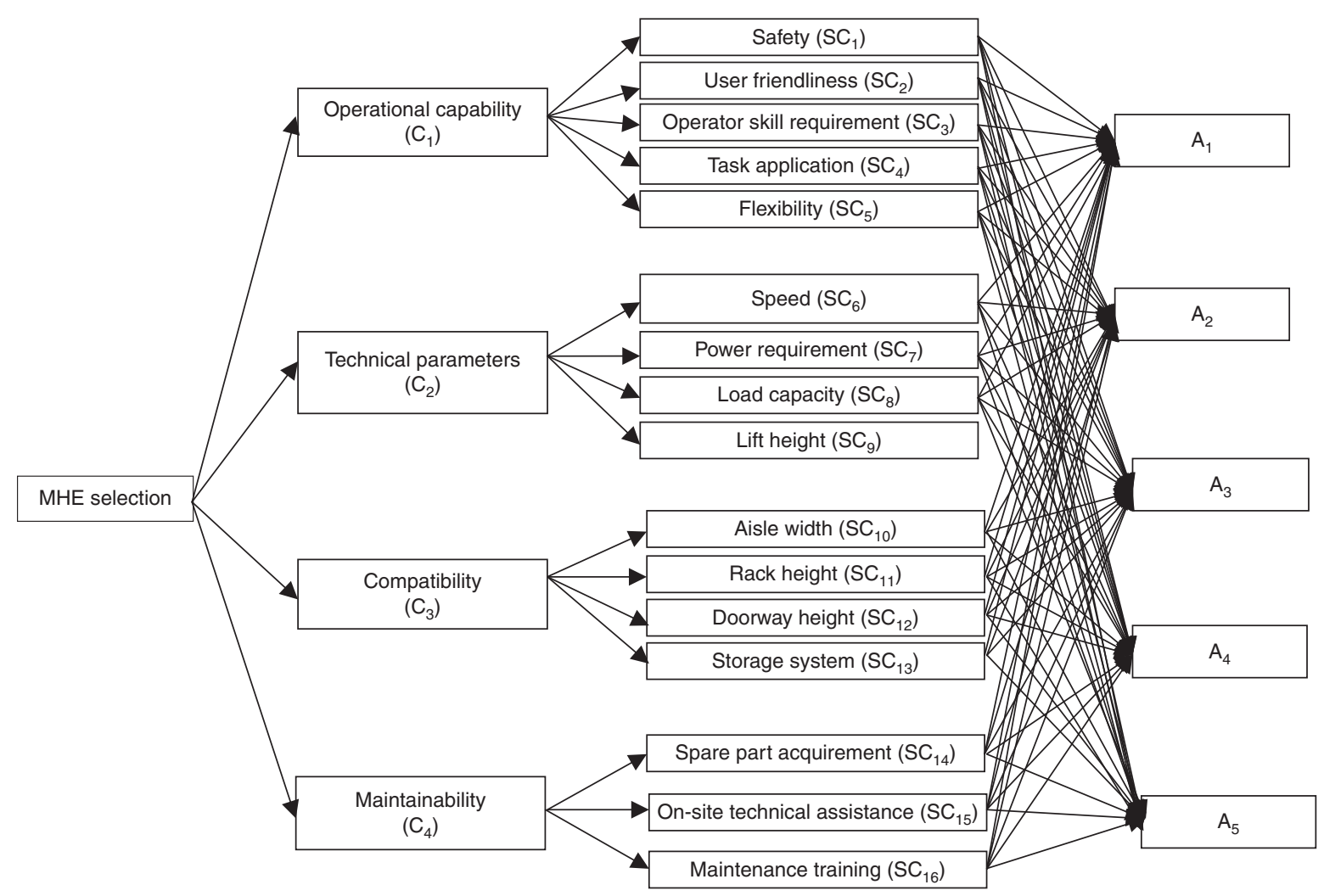

Figure 7. Hierarchy of the MHE selection problem. 
Table 4. DMs' judgment about alternatives.

\begin{tabular}{|c|c|c|c|c|c|c|c|c|c|c|c|c|c|c|c|}
\hline \multirow[b]{2}{*}{ Criteria } & \multicolumn{5}{|c|}{ DM1 } & \multicolumn{5}{|c|}{ DM2 } & \multicolumn{5}{|c|}{ DM3 } \\
\hline & $\mathrm{A}_{1}$ & $\mathrm{~A}_{2}$ & $\mathrm{~A}_{3}$ & $\mathrm{~A}_{4}$ & $\mathrm{~A}_{5}$ & $\mathrm{~A}_{1}$ & $\mathrm{~A}_{2}$ & $\mathrm{~A}_{3}$ & $\mathrm{~A}_{4}$ & $\mathrm{~A}_{5}$ & $\mathrm{~A}_{1}$ & $\mathrm{~A}_{2}$ & $\mathrm{~A}_{3}$ & $\mathrm{~A}_{4}$ & $\mathrm{~A}_{5}$ \\
\hline $\mathrm{SC}_{1}$ & MP & $\mathrm{F}$ & VG & $\mathrm{F}$ & MG & $\mathrm{F}$ & $\mathrm{F}$ & G & MG & $\mathrm{F}$ & MP & MG & VG & $\mathrm{F}$ & MG \\
\hline $\mathrm{SC}_{2}$ & G & MG & MP & $\mathrm{F}$ & G & MG & G & MP & $\mathrm{G}$ & MG & MG & MG & $\mathrm{F}$ & $\mathrm{G}$ & MG \\
\hline $\mathrm{SC}_{3}$ & $\mathrm{~F}$ & MP & VG & MG & MG & $\mathrm{F}$ & $\mathrm{F}$ & G & $\mathrm{F}$ & G & MP & MP & G & MG & G \\
\hline $\mathrm{SC}_{4}$ & MG & $\mathrm{G}$ & $\mathrm{F}$ & $\mathrm{F}$ & MG & G & MG & $\mathrm{F}$ & G & $\mathrm{F}$ & G & G & $\mathrm{F}$ & VG & $\mathrm{F}$ \\
\hline $\mathrm{SC}_{5}$ & G & MG & $\mathrm{F}$ & VG & $\mathrm{F}$ & G & MG & MG & VG & $\mathrm{F}$ & G & G & MG & MG & $\mathrm{F}$ \\
\hline $\mathrm{SC}_{6}$ & Objective rating & & Objective rating & & Objective rating & & & & & & & & & & \\
\hline $\mathrm{SC}_{7}$ & $\mathrm{G}$ & $\mathrm{F}$ & $\mathrm{F}$ & $\mathrm{F}$ & $\mathrm{F}$ & MG & MP & MP & MP & MP & $\mathrm{G}$ & $\mathrm{F}$ & $\mathrm{F}$ & $\mathrm{F}$ & $\mathrm{F}$ \\
\hline $\mathrm{SC}_{8}$ & Objective rating & & Objective rating & & Objective rating & & & & & & & & & & \\
\hline $\mathrm{SC}_{9}$ & Objective rating & & Objective rating & & Objective rating & & & & & & & & & & \\
\hline $\mathrm{SC}_{10}$ & $\mathrm{~F}$ & $\mathrm{~F}$ & G & MP & MG & $\mathrm{F}$ & MP & G & MP & G & $\mathrm{F}$ & $\mathrm{F}$ & MG & MP & MG \\
\hline $\mathrm{SC}_{11}$ & MG & $\mathrm{F}$ & MP & MG & $\mathrm{F}$ & MG & MG & MP & MG & MG & MG & $\mathrm{F}$ & MP & MG & MG \\
\hline $\mathrm{SC}_{12}$ & MG & MG & G & MG & MG & MG & MG & G & MG & MG & $\mathrm{F}$ & $\mathrm{F}$ & MG & $\mathrm{F}$ & $\mathrm{F}$ \\
\hline $\mathrm{SC}_{13}$ & $\mathrm{G}$ & G & MP & G & G & MG & MG & $\mathrm{F}$ & MG & MG & G & G & MP & G & G \\
\hline $\mathrm{SC}_{14}$ & $\mathrm{~F}$ & $\mathrm{~F}$ & F & $\mathrm{F}$ & MG & F & MG & MG & $\mathrm{F}$ & MG & MG & $\mathrm{F}$ & $\mathrm{F}$ & $\mathrm{F}$ & $\mathrm{F}$ \\
\hline $\mathrm{SC}_{15}$ & $\mathrm{~F}$ & MG & MG & $\mathrm{F}$ & MG & $\mathrm{F}$ & $\mathrm{F}$ & F & MP & MG & MP & F & $\mathrm{F}$ & $\mathrm{F}$ & MG \\
\hline $\mathrm{SC}_{16}$ & MP & $\mathrm{F}$ & MG & MP & $\mathrm{F}$ & MP & $\mathrm{F}$ & $\mathrm{F}$ & MP & MG & MP & MP & MG & MP & $\mathrm{F}$ \\
\hline
\end{tabular}

$$
\begin{gathered}
\mathrm{w}_{09}=\frac{0.0045}{0.0147+0.0463+0.0045}=0.069 \\
0 \leq w_{o j} \leq 1 ; \quad \sum_{i=1}^{n} w_{o j}=1
\end{gathered}
$$

The integrated weights are calculated as follows. The integrated weights are summarized in Table 7.

$$
\begin{aligned}
\mathrm{W} 6= & \frac{0.010 \times 0.244}{(0.010 \times 0.244)+(0.058 \times 0.707)+(0.074 \times 0.069)} \\
& \times(0.010+0.058+0.074)=0.007 \\
\mathrm{~W}_{8}= & \frac{0.058 \times 0.707}{(0.010 \times 0.244)+(0.058 \times 0.707)+(0.074 \times 0.069)} \\
& \times(0.010+0.058+0.074)=0.140 \\
\mathrm{~W}_{9}= & \frac{0.074 \times 0.069}{(0.010 \times 0.244)+(0.058 \times 0.707)+(0.074 \times 0.069)} \\
& \times(0.010+0.058+0.074)=0.017 .
\end{aligned}
$$

Regarding alternatives evaluation, alternative rating is determined through fuzzy TOPSIS corresponding to sub-criteria. Alternatives will be judged by three decision makers by using linguistic rating as shown in Table 8 . A weighted normalized fuzzy decision matrix is calculated based on the integrated weights shown in Table 8. According to fuzzy TOPSIS, the rating of alternatives can be found based on the closeness coefficient $\left(\mathrm{CC}_{i}\right)$ as follows:

\begin{tabular}{|c|c|c|c|c|c|c|}
\hline & 1 & 17 & 12 & 8.5 & 8 & 9 \\
\hline & 2 & 17.5 & 13.5 & 12 & 11 & 9.5 \\
\hline \multirow{5}{*}{ Speed $(\mathrm{km} / \mathrm{h})$} & 3 & 18 & 14 & 15.1 & 11.2 & 11 \\
\hline & 4 & 19 & 16 & 19 & 12 & 11.5 \\
\hline & 5 & 21 & 20 & 19.9 & 14 & 12 \\
\hline & 1 & 1500 & 1000 & 1300 & 1200 & 1000 \\
\hline & 2 & 3500 & 1500 & 2000 & 1400 & 1200 \\
\hline \multirow[t]{4}{*}{ Load capacity (kg) } & 3 & 5000 & 2000 & 2500 & 1600 & 1400 \\
\hline & 4 & 7000 & 6000 & 2400 & 2500 & 1800 \\
\hline & 5 & 8000 & 8500 & 3000 & 2700 & 2500 \\
\hline & 1 & 6 & 6 & 0.71 & 7.5 & 2.8 \\
\hline \multirow{2}{*}{ Lift height (m) } & 2 & 7 & 6.5 & 0.8 & 8.5 & 6.3 \\
\hline & 3 & 8 & 7.5 & 1.6 & 12.5 & 12 \\
\hline
\end{tabular}

$$
\begin{aligned}
& \mathrm{CC}_{1}=\frac{0.8014}{0.6532+0.8014}=0.55095 \\
& \mathrm{CC}_{4}=\frac{0.7853}{0.7546+0.7853}=0.55139 \\
& \mathrm{CC}_{2}=\frac{0.8342}{0.6242+0.8342}=0.57199 \\
& \mathrm{CC}_{5}=\frac{0.8389}{0.5921+0.8389}=0.58623 \\
& \mathrm{CC}_{3}=\frac{0.6738}{0.6532+0.6738}=0.47171 .
\end{aligned}
$$

\section{Second stage}

We should like to incorporate both multi-criteria and multi-objective problems based on a suitable approach through optimization. Besides finding the best alternative,

Table 5. Operating speed, load capacity and lift height of each alternative.

$$
\begin{array}{lllll}
\mathrm{A}_{1} & \mathrm{~A}_{2} & \mathrm{~A}_{3} & \mathrm{~A}_{4} & \mathrm{~A}_{5}
\end{array}
$$

(IC counter-balanced trucks) (E-counter-balanced trucks) (pallet trucks) (reach trucks) (order picker) 
Table 6. Subjective weight of sub-criteria.

\begin{tabular}{lc}
\hline Sub-criteria & Weight $(W)$ \\
\hline Safety $\left(\mathrm{sc}_{1}\right)$ & 0.263 \\
User friendliness $\left(\mathrm{sc}_{2}\right)$ & 0.141 \\
Operator skill requirement $\left(\mathrm{sc}_{3}\right)$ & 0.031 \\
Task application $\left(\mathrm{sc}_{4}\right)$ & 0.109 \\
Flexibility $\left(\mathrm{sc}_{5}\right)$ & 0.073 \\
Speed $\left(\mathrm{sc}_{6}\right)$ & 0.010 \\
Power requirement $\left(\mathrm{sc}_{7}\right)$ & 0.023 \\
Load capacity $\left(\mathrm{sc}_{8}\right)$ & 0.058 \\
Lift height $\left(\mathrm{sc}_{9}\right)$ & 0.074 \\
Aisle width $\left(\mathrm{sc}_{10}\right)$ & 0.120 \\
Rack height $\left(\mathrm{sc}_{11}\right)$ & 0.105 \\
Doorway height $\left(\mathrm{sc}_{12}\right)$ & 0.043 \\
Storage system $\left(\mathrm{sc}_{13}\right)$ & 0.322 \\
Spare part acquirement $\left(\mathrm{sc}_{14}\right)$ & 0.096 \\
On-site technical assistance $\left(\mathrm{sc}_{15}\right)$ & 0.029 \\
Maintenance training $\left(\mathrm{sc}_{16}\right)$ & 0.081 \\
\hline
\end{tabular}

determining the optimal number of MHEs is also encompassed.

According to the developed model of MHE selection, the MHE selection problem is finally constructed as follows.

Objective functions

(16) Minimize the disadvantage of material handling operation $Z_{1}(X, Y)$

$$
\begin{aligned}
& \operatorname{Min}(1-0.55095) \cdot 2 X_{1} Y_{1}+(1-0.57199) \cdot 2 \cdot X_{2} \cdot Y_{2} \\
& \quad+(1-0.47171) \cdot 2 \cdot X_{3} Y_{3}+(1-0.55139) \cdot 2 \cdot X_{4} Y_{4} \\
& \quad+(1-0.58623) \cdot 2 \cdot X_{5} \cdot Y_{5} .
\end{aligned}
$$

Table 7. Integrated weights of sub-criteria.

\begin{tabular}{lcr}
\hline Sub-criteria & Weight $(W)$ & Priority \\
\hline Safety $\left(\mathrm{sc}_{1}\right)$ & 0.263 & 2 \\
User friendliness $\left(\mathrm{sc}_{2}\right)$ & 0.141 & 3 \\
Operator skill requirement $\left(\mathrm{sc}_{3}\right)$ & 0.031 & 12 \\
Task application $\left(\mathrm{sc}_{4}\right)$ & 0.109 & 6 \\
Flexibility $\left(\mathrm{sc}_{5}\right)$ & 0.073 & 10 \\
Speed $\left(\mathrm{sc}_{6}\right)$ & $0.007 *$ & 16 \\
Power Requirement $\left(\mathrm{sc}_{7}\right)$ & 0.023 & 14 \\
Load Capacity $\left(\mathrm{sc}_{8}\right)$ & $0.140^{*}$ & 4 \\
Lift Height $\left(\mathrm{sc}_{9}\right)$ & $0.017^{*}$ & 15 \\
Aisle width $\left(\mathrm{sc}_{10}\right)$ & 0.120 & 5 \\
Rack Height $\left(\mathrm{sc}_{11}\right)$ & 0.105 & 7 \\
Door way height $\left(\mathrm{sc}_{12}\right)$ & 0.043 & 11 \\
Storage system $\left(\mathrm{sc}_{13}\right)$ & 0.322 & 1 \\
Spare part Acquirement $\left(\mathrm{sc}_{14}\right)$ & 0.096 & 8 \\
On-site technical assistance $\left(\mathrm{sc}_{15}\right)$ & 0.029 & 13 \\
Maintenance training $\left(\mathrm{sc}_{16}\right)$ & 0.081 & 9 \\
\hline
\end{tabular}

* Indicates integration of objective and subjective weight.

Table 8. Linguistic variables for the importance weight of the criteria.

\begin{tabular}{lc}
\hline Linguistic variable & Corresponding TFN \\
\hline Very Poor (VP) & $(0,0,1)$ \\
Poor (P) & $(0,1,3)$ \\
Medium Poor (MP) & $(1,3,5)$ \\
Fair (F) & $(3,5,7)$ \\
Medium Good (MG) & $(5,7,9)$ \\
Good (G) & $(7,9,10)$ \\
Very Good (VG) & $(9,10,10)$ \\
\hline
\end{tabular}

(17) Minimize the total cost of material handling $Z_{2}(X, Y)$

$$
\begin{aligned}
\text { Min } & X_{1} \cdot Y_{1}\left(\frac{15,000-8500}{1584}+19\right) \\
+ & \left(\frac{42 \times 30.3+58 \times 24.5}{X_{1} \cdot 2}\right) 12.5 \cdot Y_{1} \\
+ & \left(\frac{42 \times 31.7+58 \times 25.7}{X_{2} \cdot 2}\right) 17.82 \cdot Y_{2} \\
+ & X_{3} \cdot Y_{3}\left(\frac{8200-3800}{1584}+9.55\right) \\
+ & \left(\frac{42 \times 33.4+58 \times 27}{X_{3} \cdot 2}\right) 13.64 \cdot Y_{3} \\
+ & X_{4} \cdot Y_{4}\left(\frac{10,000-4800}{1584}+10.68\right) \\
+ & \left(\frac{42 \times 44.6+58 \times 36}{X_{4} \cdot 2}\right) 13.64 \cdot Y_{4} \\
+ & X_{5} \cdot Y_{5}\left(\frac{18,000-6700}{1584}+10.68\right) \\
+ & \left(\frac{42 \times 52.4+58 \times 42.4}{X_{5} \cdot 2}\right) 13.64 \cdot Y_{5}
\end{aligned}
$$

s.t.

$$
\begin{aligned}
& Y_{1}+Y_{2}+Y_{3}+Y_{4}+Y_{5}=1 \\
& 0.85 \cdot 480 \leq Y_{1}\left(\frac{42 \times 30.3+58 \times 24.5}{X_{1} \cdot 2}\right) \\
& \quad+Y_{2}\left(\frac{42 \times 31.7+58 \times 25.7}{X_{2} \cdot 2}\right) \\
& \quad+Y_{3}\left(\frac{42 \times 33.4+58 \times 27}{X_{3} \cdot 2}\right) \\
& \quad+Y_{4}\left(\frac{42 \times 44.6+58 \times 36}{X_{4} \cdot 2}\right) \\
& \quad+Y_{5}\left(\frac{42 \times 52.4+58 \times 42.4}{X_{5} \cdot 2}\right) \leq 480 \\
& \quad+Y_{5} \cdot 4.76 \geq 2.9 \\
& \quad 3.035+Y_{2} \cdot 3.310+Y_{3} \cdot 0.235+Y_{4} \cdot 4.4 \\
& Y_{1} \cdot 1.14+Y_{2} \cdot 1.14+Y_{3} \cdot 1.14+Y_{4} \cdot 1.14 \\
& +Y_{5} \cdot 1.14 \geq 2.8 \\
& Y_{1} \cdot 6+Y_{2} \cdot 4+Y_{3} \cdot 8+Y_{4} \cdot 5+Y_{5} \cdot 4 \geq 2 \\
& Y_{1} \cdot 3.39+Y_{2} \cdot 2.7+Y_{3} \cdot 2.247+Y_{4} \cdot 2.779 \\
& +Y_{5} \cdot 3.12 \geq 2.8 \\
& X_{1}, X_{2}, X_{3}, X_{4}, X_{5} \geq 0 \text { and integer } \\
& Y_{1}, Y_{2}, Y_{3}, Y_{4}, Y_{5}=0 \text { or } 1 .
\end{aligned}
$$

To solve the MOMILP model above, the AUGMECON procedure is used. First, a payoff table is constructed by a lexicographic method wherein the prioritized objective function addresses minimizing the disadvantage of material handling operation $\left(Z_{1}\right)$. Then, the MOMILP model $Z_{1}\left(e_{1}\right)$ is transformed to become

$$
\begin{aligned}
& \operatorname{Min}\left(Z_{1}(x)+\text { eps }\left(\frac{s_{p 2}}{r_{2}}\right)\right) \\
& \text { s.t. } \quad Z_{2}(x)+s_{p 2}=e_{2}
\end{aligned}
$$




$$
\begin{array}{ll}
\text { Min } & (1-0.55095) \cdot 2 \mathrm{Y}_{1}+(1-0.57199) \cdot 2 \mathrm{Y}_{2} \\
+ & (1-0.47171) \cdot 2 \cdot \mathrm{Y}_{3}+(1-0.55139) \cdot 2 \cdot \mathrm{Y}_{4} \\
+ & (1-0.58623) \cdot 2 \cdot \mathrm{Y}_{5}+10^{-4}\left(\frac{s_{\mathrm{p} 2}}{0.00079}\right) \\
\text { s.t. } & X_{1} \cdot Y_{1}\left(\frac{15,000-8500}{1584}+19\right) \\
+ & \left(\frac{42 \times 30.3+58 \times 24.5}{X_{1} \cdot 2}\right) 0.025 \cdot Y_{1} \\
+ & X_{2} \cdot Y_{2}\left(\frac{20,000-10,000}{1584}+24.32\right) \\
+ & \left(\frac{42 \times 31.7+58 \times 25.7}{X_{2} \cdot 2}\right) 0.037 \cdot Y_{2} \\
+ & X_{3} \cdot Y_{3}\left(\frac{8200-3800}{1584}+9.55\right) \\
+ & \left(\frac{42 \times 33.4+58 \times 27}{X_{3} \cdot 2}\right) 0.027 \cdot Y_{3} \\
+ & X_{4} \cdot \mathrm{Y}_{4}\left(\frac{10,000-4800}{1584}+10.68\right) \\
+ & \left(\frac{42 \times 44.6+58 \times 36}{X_{4} \cdot 2}\right) 0.028 \cdot Y_{4} \\
+ & \mathrm{s}_{\mathrm{p} 2} \cdot Y_{5}\left(\frac{18,000-6700}{1584}+10.68\right) \\
+ & \left(\frac{42 \times 52.4+58 \times 42.4}{X_{5} \cdot 2}\right) 0.028 \cdot Y_{5} \\
+ & \left.\frac{403.657}{2}\right) \\
+ & \\
+ &
\end{array}
$$

The solution is obtained by using LINGO software. The result shows that the best MHE for warehouse operation in the company, particularly for transport, loading and unloading, is $\mathrm{A}_{2}$. Based on the LINGO software output, objective value achievement for objective functions $1\left(Z_{1}\right)$ and $2\left(Z_{2}\right)$ are, respectively, 2.568060 and $\$ 103.6577$ per day. The number of MHEs required $\left(A_{2}\right)$ is three units.

\section{Results and discussion}

Our first discussion relates to the final alternatives selection of multi-criteria decision making through entropy based hierarchical fuzzy TOPSIS by applying subjective and integrated weights of sub-criteria, and comparison of the result is explained explicitly. Subjective weights are obtained by using fuzzy AHP, while integrated weights are an integration of subjective and objective weights obtained by using the entropy method. By using the same procedure of hierarchical fuzzy TOPSIS, for instance, the result of alternatives rating and ranking corresponding to subjective weights and integrated weights are compared in Table 9.

The decision would be more distracting if the problem were multi-alternatives selection, meaning more than one alternative to be chosen. In this context, looking at the different considerations of the weights of evaluation criteria determination such as in Table 9 literally brings a different ranking order of alternatives. In the case of applying subjective weights of criteria, A5 and A2 can be
Table 9. Comparison of alternatives ranking using different weights of sub-criteria.

\begin{tabular}{lccccc}
\hline & \multicolumn{2}{c}{ Subjective weight } & & \multicolumn{2}{c}{ Integrated weight } \\
\cline { 2 - 3 } Alternatives & Rating & Rank & & Rating & Rank \\
\hline $\mathrm{A}_{1}$ & $0.550,95$ & 4 & & $0.554,51$ & 4 \\
$\mathrm{~A}_{2}$ & $0.571,99$ & 2 & & $0.577,83$ & 3 \\
$\mathrm{~A}_{3}$ & $0.471,71$ & 5 & & $0.471,01$ & 5 \\
$\mathrm{~A}_{4}$ & $0.551,39$ & 3 & & $0.579,79$ & 2 \\
$\mathrm{~A}_{5}$ & $0.586,23$ & 1 & & $0.607,42$ & 1 \\
\hline
\end{tabular}

taken for granted whereas A5 and A4 are eligible for selection in accordance with integrated weights.

With a view to comprehensive decision making, the selection process is conducted by considering holistic parameters. From this viewpoint, alternatives selection is expected to be able to contribute to the continuity of warehouse operations as well as the handling of material, and the expense of the alternatives should be commensurate with the value attributed to the material, the operator and the operations themselves. In other words, the alternatives should meet both objectives, i.e. minimization of the disadvantage of material handling operation and the total cost of material handling. To achieve these objectives, the MHE selection problem is translated into an MOMILP problem. MOMILP was developed for a real case of MHE selection problem. The developed model aims to seek the best alternatives satisfying both the objective functions and to determine the required number of alternatives. The MOMILP model is solved through the AUGMECON method so that the superior objective, i.e. minimization of the disadvantage of material handling operation (objective 1), can be achieved first, and that the minimization of material handling cost (objective 2) can be subsequently satisfied.

We delved into the final solution by using MOMILP when the different rating of alternatives derived from subjective and integrated weights was compiled into the developed model. By using LINGO software, the solutions for both scenarios suggest the same alternatives to be selected. Finally, the solution brings to the MHE selection problem a comprehensive and holistic selection process by offering the best one. The final result of alternatives selection through AUGMECON shows that the most suitable MHE for warehouse operations is A2. The required number of $\mathrm{A} 2$ is three units. The optimal number of MHEs is calculated to fulfil the warehouse operation in terms of handling product received and shipping within eight working hours. The achievement values for objective 1 and objective 2, respectively, are 2.568060 and $\$ 103.6577$ per day.

If we look at the first stage of alternatives selection conducted by using hierarchical fuzzy TOPSIS, there is an extremely different result. It is admitted that A5 is the most suitable alternative. But it is no longer visible since the minimum total cost of material handling could not be attributed to A5. For complex decision making, alternatives selection cannot be established only by using a stand- 
alone MCDM method because most MCDM methods only account for evaluation through subjective human judgment instead of through exact quantified algorithms.

In addition, as discussed further, the complexity of decision making will increase for multiple alternatives selection. Applying different weights of evaluation criteria will result in different ranking orders of alternatives. Two scenarios were considered by applying subjective weights and integrated weights to clarify the superiority of the proposed hybrid method in finding the most suitable alternative. The visible solution was derived from an extended approach according to optimization using AUGMECON. The result gave the same solution for both scenarios. This indicates that using the extended approach for MCDM as well as optimization can lessen the dilemma posed by the selection of alternatives, which may lead to improper decision making, and offer a more accurate solution.

\section{Conclusions}

In this study, the MHE selection problem is defined as a multi-criteria and multi-objective decision problem. The extension of fuzzy TOPSIS in determining the weight of sub-criteria through fuzzy AHP and the entropy method is thoroughly remarkable. It is really useful to buttress DMs' arbitrary opinions.

In view of comprehensive decision making, the selection process is conducted by considering holistic parameters. From this perspective, the problem is defined as multi-criteria and multi-objective alternatives selection so that performance feasibility and economic feasibility can be achieved.

The contribution of MHEs should ensure the continuity of warehouse operations as well as the handling of material, and the expense of alternatives should be commensurate with the value attributed to the material, operator and the operations themselves. In other words, the alternatives should meet both objectives. To achieve those objectives, the MHE selection problem is translated into an MOMILP problem. MOMILP was developed for a real case of the MHE selection problem. Finally, the solution brings to the MHE selection problem a comprehensive and holistic selection process by offering the best one. The hybrid method of integrating entropy based hierarchical fuzzy TOPSIS and MOMILP brings enormous advantages for MHE selection:

(1) the proposed hybrid method can represent the actual data provided in the criteria evaluation and provide more measured weights of criteria;

(2) the MCDM method cannot provide better result for complex MHE selection problem if it stands alone. Hence, the integration of entropy based hierarchical fuzzy TOPSIS and MOMILP can provide more accurate results;

(3) the proposed hybrid method is capable of fulfilling the performance measure of the most suitable MHE in terms of operational capability, technical parameters, compatibility, maintainability and cost as well;

(4) the hybrid method not only attempts to find the most suitable MHEs, but also to determine the optimum number of MHEs.

Future work is expected to improve the current study. The current study has developed a model for the MHE selection problem in a warehouse for just a single product. The hybrid model may be improved for MHE selection with heterogeneous or multiple products in a warehouse. However, there are several other methods of MCDM, such as PROMETHEE, ELECTRE, ANP and many more, which may be able to be combined within an optimization method.

\section{Funding}

The authors would like to thank the Directorate General of Higher Education (DGHE) of Indonesia under the program 'Beasiswa Unggulan Luar Negeri DIKTI' for partial grant support of the work entailed in accomplishing this paper.

\section{Disclosure statement}

No potential conflict of interest was reported by the authors.

\section{References}

Akman, G., \& Baynal, K. (2014). Logistics service provider selection through an integrated fuzzy multi criteria decision making approach. Journal of Industrial Engineering, 2014, Article ID 794918, 1-16. Retrieved from http://dx.doi.org/ $10.1155 / 2014 / 794918$

Ballı, S., \& Korukoğlu, S. (2009). Operating system selection using fuzzy AHP and TOPSIS methods. Mathematical and Computational Applications, 14(2), 119-130.

Braglia, M., Gabbrielli, R., \& Miconi, D. (2001). Material handling device selection in cellular manufacturing. Journal of Multi-Criteria Decision Analysis, 10, 303-315. Retrieved from http://dx.doi.org/10.1002/mcda.310

Buckley, J. -J. (1985). Fuzzy hierarchical analysis. Fuzzy Sets and Systems, 17(3), 233-247. Retrieved from http://dx.doi. org/10.1016/0165-0114(85)90090-9

Chakraborty, S., \& Banik, D. (2006). Design of a material handling equipment selection model using analytic hierarchy process. International Journal of Advanced Manufacturing Technology, 28, 1237-1245. Retrieved from http://dx.doi. org/10.1007/s00170-004-2467-y

Chankong, V., \& Haimes, Y. (1983). Multi-Objective Decision Making Theory and Methodology. New York: Elsevier Science.

Cunbin, L., \& Peng, L. (2012). Research on risk element transmission of enterprise project evaluation chain based on trapezoidal fuzzy number FAHP. Research Journal of Applied Sciences, Engineering and Technology, 4(14), 2153-2159.

Ding, J. -F. (2011). An integrated fuzzy TOPSIS method for ranking alternatives and its application. Journal of Marine Science and Technology, 19(4), 341-352.

Do, H. Q., Chen, J. -F., \& Hsieh, H. -N. (2015). Evaluating teaching performance based on fuzzy AHP and comprehensive evaluation approach. Applied Soft Computing, 28, $100-108$.

Ehrgott, M., \& Wiecek, M. (2005). Multiobjective programming. In J. Figueira, S. Greco, \& M. Ehrgott (Eds.), Multiple Criteria Decision Analysis: State of the Art Surveys (pp. 667-722). Dordrecht: Springer.

Erdebilli, B., \& Saputro, T. E. (2014). Supplier selection using integrated fuzzy TOPSIS and MCGP, a case study. Procedia - Social and Behavioural Sciences, 116(21), 3957-3970. 
Ertugrul, I., \& Oztas, T. (2014). Business mobile-line selection in Turkey by using fuzzy TOPSIS, one of the multi-criteria decision methods. Procedia - Computer Science, 31, 40-47.

Feizizadeh, B., Roodposhti, S. M., Jankowski, P., \& Blaschke, T. (2014). A GIS-based extended fuzzy multi-criteria evaluation for landslide susceptibility mapping. Computers \& Geosciences, 73, 208-221. Retrieved from http://dx.doi.org/ 10.1016/j.cageo.2014.08.001

Guo, S., \& Zhao, H. (2014). Selecting green supplier of thermal power equipment by using a hybrid MCDM method for sustainability. Sustainability, 6, 217-235. Retrieved from http://dx.doi.org/10.3390/su6010217

Hwang, C. L., \& Yoon, K. P. (1981). Multiple Attribute Decision Making: Methods and Applications. New York: SpringerVerlag.

Jadidi, O., Hong, T. S., Firouzi, F., Yusuff, R. M., \& Zulkifli, N. (2008). TOPSIS and fuzzy multi-objective model integration for supplier selection problem. Journal of Achievements in Materials and Manufacturing Engineering, 31(2), 762-769.

Karande, P., \& Chakraborty, S. (2013). Material handling equipment selection using weighted utility additive theory. Journal of Industrial Engineering. Article ID 268708, 1-9. Retrieved from http://dx.doi.org/10.1155/ $2013 / 268708$

Kulak, O. (2005). A decision support system for fuzzy multiattribute selection of material handling equipments. Expert Systems with Applications, 29(2), 310-319.

Kumar, S., \& Joshi, D. (2014). Intuitionistic fuzzy entropy and distance measure based TOPSIS method for multicriteria decision making. Egyptian Informatics Journal, 15, 97-104.

Kutlu, A. C., \& Ekmekçioğlu, M. (2012). Fuzzy failure modes and effects analysis by using fuzzy TOPSIS-based fuzzy AHP. Expert Systems with Applications, 39, 61-67.

Laarhoven, P. J. M., \& Pedrycz, W. (1983). A fuzzy extension of Saaty's priority theory. Fuzzy Sets and Systems, 11, 229-241.

Li, Y. (2014). Service quality measurement using fuzzy AHPbased approach. Journal of Computers, 9(7), 1697-1703.

Li, Y., \& Ye, F. (2014). An extended TOPSIS model based on the possibility theory under fuzzy environment. KnowledgeBased Systems, 67, 263-269.

Matson, J. O., Mellichamp, J. M., \& Swaminatham, S. R. (1992). EXCITE, Expert consultant for in plant transportation equipment. International Journal of Production Research, 30(8), 1969-1983.

Mavrotas, G. (2009). Effective implementation of the e-constraint method in multi-objective mathematical programming problems. Applied Mathematics and Computation, 213, 455-465.

Miettinen, K. M. (1998). Nonlinear Multi-Objective Optimization. Boston, MA: Kluwer Academic.

Mohaghar, A., Fathi, M. R., Faghih, A., \& Turkayesh, M. M. (2012). An integrated approach of fuzzy ANP and fuzzy TOPSIS for R\&D project selection, a case study. Australian Journal of Basic and Applied Sciences, 6(2), 66-75.

Mohammadi, A., Mohammadi, A., Mohammadi, M., \& Mohammadi, A. (2011). Australian Journal of Basic and Applied Sciences, 5(11), 2026-2035.

Momani, A. M., \& Ahmed, A. A. (2011). Material handling equipment selection using hybrid Monte Carlo simulation and analytic hierarchy process. Engineering and Technology, $59,644-649$.

Önüt, S., Kara, S. S., \& Isik, E. (2009). Long term supplier selection using a combined fuzzy MCDM approach: A case study for a telecommunication company. Expert Systems with Applications, 36, 3887-3895. Retrieved from http://dx. doi.org/10.1016/j.eswa.2008.02.045

Pan, N. -F. (2008). Fuzzy AHP approach for selecting the suitable bridge construction method. Automation in Construction, $17(8), 958-965$.

Saaty, T. L. (1980). The Analytic Hierarchy Process. New York: McGraw-Hill.

Shaverdi, M., Heshmatib, M. R., \& Ramezanic, I. (2014). Application of fuzzy AHP approach for financial performance evaluation of Iranian petrochemical sector. Procedia Computer Science, 31, 995-1004.

Shemshadi, A., Toreihi, M., Shirazi, H., \& Tarokh, M. J. (2011). Supplier selection based on supplier risk: An ANP and fuzzy TOPSIS approach. Journal of Mathematics and Computer Science, 2(1), 111-121.

Shih, H., Shyur, H., \& Lee, E. (2007). An extension of TOPSIS for group decision making. Mathematical and Computer Modelling, 45, 801-813.

Song, W., Minga, X., Wua, Z., \& Zhua, B. (2013). Failure modes and effects analysis using integrated weight-based fuzzy TOPSIS. International Journal of Computer Integrated Manufacturing, 26(12), 1172-1186.

Song, Z., Zhu, H., Jia, G., \& He, C. (2014). Comprehensive evaluation on self-ignition risks of coal stockpiles using fuzzy AHP approaches. Journal of Loss Prevention in the Process Industries, 32, 78-94.

Sun, C.-C. (2010) A performance evaluation model by integrating fuzzy AHP and fuzzy TOPSIS methods. Expert Systems with Applications, 37, 7745-7754.

Taylan, O., Bafail, A. O., Abdulaal, R. M. S., \& Kabli, M. R. (2014). Construction projects selection and risk assessment by fuzzy AHP and fuzzy TOPSIS methodologies. Applied Soft Computing, 17, 105-116.

Tian, Z., Zheng, G., Zhu, N., Chen, Y., \& Sun, B. (2012). Application of a trapezoidal fuzzy AHP method for work safety evaluation and early warning rating of hot and humid environments. Safety Science, 50(2), 228-239.

Tolga, A. C., \& Kahraman, C. (2008). Fuzzy multiattribute evaluation of $R \& D$ projects using a real options valuation model. International Journal of Intelligent Systems, 23, $1153-1176$.

Tompkins, J. A., White, Y. A., Bozer, J. M., \& Tanchoco, A. (2003). Facilities Planning. New York: Wiley.

Vieira, G. B. B., Pasa, G. S., Borsa, M. B. N. O., Milan, G. S., \& Pandolfo, A. (2011). Materials handling management: A case study. Journal of Operations and Supply Chain Management, 4(2), 19-30.

Wang, X., Chan, K. H., \& Li, D. (2015). A case study of an integrated fuzzy methodology for green product development. European Journal of Operational Research, 241, 212-223.

Wang, C. -H., \& Wang, J. (2014). Combining fuzzy AHP and fuzzy Kano to optimize product varieties for smart cameras: A zero-one integer programming perspective. Applied Soft Computing, 2, 410-416.

Xu, Z., \& Zhang, X. (2015). Soft computing based on maximizing consensus and fuzzy TOPSIS approach to interval-valued intuitionistic fuzzy group decision making. Applied Soft Computing, 26, 42-56.

Yazdian, S. A., \& Shahanaghi, K. (2009). Vendor selection using a new fuzzy group TOPSIS approach. Journal of Uncertain Systems, 3(3), 221-231.

Zadeh, L. A. (1965). Fuzzy sets. Information Control, 8, 338-353.

Zou, Z. H., Yun, Y., \& Sun, J. N. (2006). Entropy method for determination of weight of evaluating indicators in fuzzy synthetic evaluation for water quality assessment. Journal of Environmental Sciences (China), 18, 1020-1023. 